\title{
The transcription factor CF2 is a mediator of EGF-R-activated dorsoventral patterning in Drosophila oogenesis
}

\author{
Tien Hsu, ${ }^{1,4,5}$ Claudia Bagni, ${ }^{2,3,4}$ James D. Sutherland, ${ }^{2}$ and Fotis C. Kafatos ${ }^{2}$ \\ ${ }^{1}$ Center for Molecular and Structural Biology and Department of Experimental Oncology, Medical University of South \\ Carolina, Charleston, South Carolina 29425 USA; ${ }^{2}$ Department of Molecular and Cell Biology, Harvard University, Boston, \\ Massachusetts 02138 USA and European Molecular Biology Laboratory, 69012 Heidelberg, Germany
}

Establishment of dorsoventral polarity during Drosophila oogenesis requires localized intercellular communication between the follicular cells and the oocyte. This is initiated by the transmission of a "dorsal signal" from the oocyte to the anterior dorsal follicle cells by the EGF receptor (EGF-R) pathway and is followed by transmission of a second signal from the ventral follicle cells back to the embryo. We show that the zinc finger transcription factor CF2 participates in these processes. CF2 is suppressed by EGF-R signaling in the anterior dorsal follicle cells. Altered expression patterns of CF2 result in specific dorsoventral patterning defects in egg chambers and in embryos, as demonstrated phenotypically and with molecular markers. CF2 appears to act as a repressor of dorsal follicle cell fates and specifically as a repressor of the rhomboid gene transcription.

[Key Words: Dorsoventral patterning; EGF receptor signaling; oogenesis; transcription repression]

Received March 11, 1996; revised version accepted April 23, 1996.

Dorsoventral (D/V) pattern in the Drosophila egg chamber, which also affects subsequent embryogenesis, is generated through the action of $\geqslant 20$ maternal-effect genes (for reviews, see Schüpbach et al. 1991; Chasan and Anderson 1993). This pattern is initiated at stages 8-9 of oogenesis, when the oocyte nucleus migrates to an anterodorsal position. Soon afterward gurken $(g r k)$ RNA and the protein it encodes, a transforming growth factor $\alpha(T G F \alpha)$-like ligand, become similarly localized in the anterodorsal region of the oocyte neighboring the nucleus (Neuman-Silberberg and Schüpbach 1993; González-Reyes et al. 1995; Roth et al. 1995). Localization of grk RNA is the critical step and is ensured by at least three mechanisms: (1) mRNA synthesis in the dorsally positioned nucleus; (2) action of the $f_{s}(1) K 10$ (henceforth $\mathrm{K10}$ ) gene product probably to reduce transcription (Prost et al. 1988; Forlani et al. 1993); and (3) prevention of mRNA diffusion to the ventral side through the actions of at least four genes: spire (spir), cappuccino (capu), orb, and squid (sqd) (Manseau and Schüpbach 1989; Kelly 1993; Neuman-Silberberg and Schüpbach 1993; Christenson and McKearin 1994; Roth and Schüpbach 1994).

The spatially localized Grk protein activates in the facing anterior dorsal follicle cells the membrane-bound,

\footnotetext{
${ }^{3}$ Present address: Department of Biology, Universitá Tor Vergata, Rome, Italy.

${ }^{4}$ These authors contributed equally to this work.

${ }^{5}$ Corresponding author.
}

ubiquitous epidermal growth factor receptor (EGF-R) that is encoded by the torpedo (top) locus (Price et al. 1989|. Grk binding initiates the EGF-R signal transduction pathway, which involves homologs of Ras, Raf, and MEK (Brand and Perrimon 1994; Hsu and Perrimon 1994; for review, see Perrimon 1994), and ultimately establishes the dorsal fate of the follicular cells. In mutants such as $K 10$ and spir, the grk RNA and presumably the Grk protein spread to the ventral side of the oocyte, resulting in dorsalized egg chambers (Neuman-Silberberg and Schüpbach 1993; Roth and Schüpbach 1994). Dorsal fate is manifested by specialized chorion structures elaborated by the follicular cells, such as the respiratory dorsal appendages (Margaritis et al. 1980). Another transmembrane protein, encoded by rhomboid (rho), is expressed in the follicle cells where top is activated and probably serves to amplify the dorsal signal (RuoholaBaker et al. 1993).

In contrast, when gene functions such as grk, top, Draf, and rho are absent, dorsal cell fates are insufficiently defined and the egg chamber becomes ventralized (Schüpbach 1987; Ruohola-Baker et al. 1993; Brand and Perrimon 1994). These mutations, as well as K10 and spir, also result in corresponding embryonic phenotypes, indicating that the $\mathrm{D} / \mathrm{V}$ patterning processes in the egg chamber and embryo are coupled, through the EGF-R signaling pathway (Schüpbach and Wieschaus 1989, $1991)$.

Because the Grk ligand is localized dorsally, the ventral follicle cells do not normally experience EGF-R sig- 
naling. Instead, they undergo a ventral-specific signaling process that activates ultimately an embryonic membrane receptor, the Toll gene product (Hashimoto et al. 1991; Schneider et al. 1991). Toll activation results in translocation of the transcription factor Dorsal into the nuclei of the syncytial blastoderm, in a gradient that specified localized expression of different sets of zygotic genes [e.g., twist (twi) ventrally and decapentaplegic $(d p p)$ dorsally], ultimately leading to $\mathrm{D} / \mathrm{V}$ differentiation of embryonic structures (Jiang et al. 1991).

Although many components of these pathways have been described, an important gap is that no transcriptional regulators have been identified in follicular cells, which are either controlled by the dorsal signal or themselves control ventral signal production. It is likely that transcription factors that are critical for the maternal $\mathrm{D} / \mathrm{V}$ patterning processes are also essential for other events in embryonic and postembryonic development (Ruohola-Baker et al. 1994). Mutations in these factors might result in lethality, precluding detection of their effects on oogenesis, which occurs at a late stage of the life cycle. We examined a collection of transcription factors that are expressed in the ovaries (Shea et al. 1990), and noted that a nuclear zinc finger protein CF2 (Hsu et al. 1992) shows spatially restricted expression in the follicular epithelium, suggesting a role in spatial patterning. Here we demonstrate that indeed CF2 is involved in this process in a manner that may help explain the development of both follicular and embryonic $D / V$ patterning.

\section{Results}

Expression of the transcription factor CF2 is regulated spatially by the EGF-R pathway

$\mathrm{CF} 2$ is a $\mathrm{Cys}_{2}-\mathrm{His}_{2}$ zinc finger protein defined initially by virtue of its sequence-specific binding to the promoter of the chorion (eggshell) protein gene s15 (Shea et al. 1990). Although its functional role in chorion gene expression has not been demonstrated in vivo, immunocytochemistry identified CF2 in the nuclei of follicle cells that surround the oocyte and produce the chorion. Interestingly, CF2 protein is detected initially at early stage 8 of oogenesis in all the follicle cells that surround the oocyte, but later becomes spatially restricted; at late stage 9 and early stage 10 it disappears from the anterodorsal follicle cells, creating a prominent negative "patch" at least through stage 12 (arrow in Fig. 1, left column).

The patch corresponds to the region where the oocyte and the somatic follicle cells communicate through the EGF-R signaling pathway, resulting in the determination of dorsal follicle cell fates. We showed that mutations involving this pathway affect the localized depletion of CF2; the CF2-negative patch expands into the ventral region in the dorsalized mutants spir and especially $K 10$, in pace with the expansion of dorsal cell fate (Fig. 1, middle column). Conversely, the patch shrinks in ven- tralized mutants and is completely eliminated in strong mutants of grk and top (Fig. 1, right column).

CF2 protein functions as a repressor of dorsally expressed genes

The observations indicated that CF2 is depleted as a result of EGF-R signaling. Manipulation of CF2 levels indicated further that CF2 can quickly repress (directly or indirectly) gene activities that are associated with the dorsal cell fate; rho, which is first induced at stage 10 and is required for the dorsal fates of the anterodorsal cells (Ruohola-Baker et al. 1993; Brand and Perrimon 1994), and the enhancer trap insert in line AN296 (Bier et al. 1989|, which responds in a cell-autonomous fashion to alterations in the activity of the EGF-R pathway (J. Duffy and N. Perrimon, pers. comm.). For these experiments we used CF2 sense and antisense constructs directed by an $h s p 70$ promoter (henceforth CF2-s and CF2-as, respectivelyl; we confirmed that $C F 2$-s induction results in the presence of CF2 in all follicular cells, whereas CF2-as induction depletes CF2 in ventral as well as dorsal cells, especially in the anterior region (Fig. 1, lower right and middle). As shown in Figure 2, at stage 10 and within 2 hr of the heat shock, overexpression of CF2 (CF2-s) represses both AN296 and rho expression in the anterior dorsal follicle cells, whereas depletion of CF2 (CF2-as) causes AN296 expression to spread ventrally and posteriorly, and rho expression to become generalized in the follicular epithelium. At stage 11, normal rho expression consists of two elements: a thin anterior layer of cells, between the nurse cells and the oocyte, and a V-shaped "double stripe", corresponding to the dorsal appendages (Ruohola-Baker et al. 1993). The former remains immediately susceptible to CF2 repression but, interestingly, the double stripe loses susceptibility to CF2 once the dorsal fate has been established at stage 10 (Fig. 2). If CF2-s is induced $10 \mathrm{hr}$ earlier (i.e., at stage 9-10a), the double stripe at stage 11 is suppressed (data not shown).

\section{Ectopic expression or depletion of CF2 alter} the $D / V$ polarity of the egg chamber

We examined whether ectopic overexpression or depletion of CF2 during oogenesis might alter D/V polarity of the egg chamber. Such effects were seen, which for simplicity will be summarized as dorsalization or ventralization, respectively (see also Discussion).

In the top and grk ventralized mutants, egg chambers become elongated in shape, their dorsal appendages fuse and shrink, and the number of main body follicle cells increases (Fig. 3; Table 1). When CF2 protein was overexpressed from two copies of the CF2-s transgene, a high proportion of the egg chambers showed at least moderate ventralization, in all three respects (CF2-s; Fig. 3; Table 1). These phenocopies were attributable to CF2 overexpression, as they were almost never seen in the identically heat-shocked parental strain ( $y w$; Figs. 3 and 4) or in the same CF2-s strain without heat shock (results not shown). At least two transgenic lines were used in these and subsequent experiments, with consistent results. 

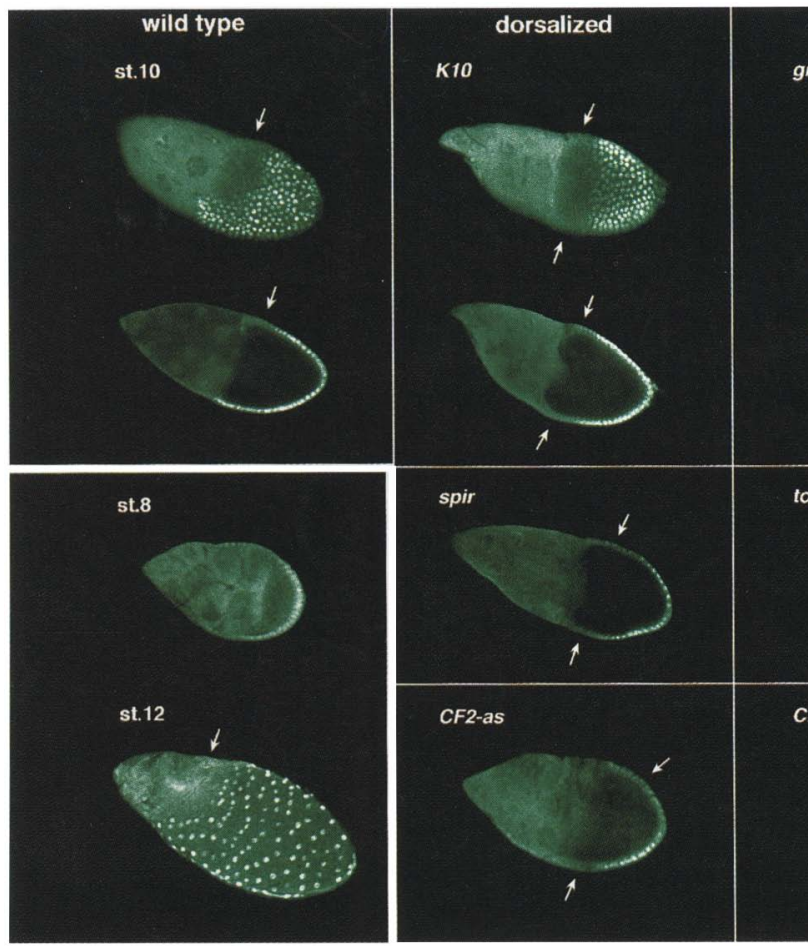

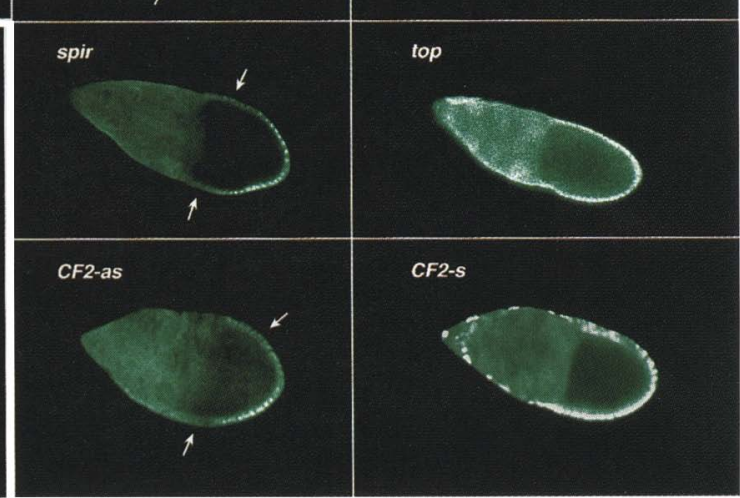

Figure 1. CF2 protein distribution in wild-type and dorsoventral polarity mutant egg chambers. All egg chambers were stained with CF2 monoclonal antibody and examined laterally by confocal microscopy. Anterior is to the left and dorsal side is up. Phenotypes are indicated at the top of the three columns and genotypes in individual panels. Note that CF2 is mostly nuclear. Arrows point to areas in the oocyte-associated follicle cell layer where CF2 expression is depleted. Panels in the top row show a surface view and an optical cross section of the same egg chamber. All other egg chambers except the wild type at stage 12 (bottom left) are shown in optical cross section. In the wild type, CF2 appears at early stage 8 in the oocyte-associated follicle cells (bottom left), but by early stage 10, CF2 it disappears from an anterodorsal patch of follicle cells $(t o p$ left $)$; this feature persists at least through stage 12 (bottom left). In dorsalized mutants, the CF2-depleted patch is more extensive; in $K 10$ (top middle), it spreads ventrally to become a distinct band surrounding the anterior region of the oocyte, but in spir the boundary between CF2 expressing and nonexpressing cells is less well defined (middle). Similar spreading of the patch results by inducing high levels of CF2 antisense RNA from an hsp 70 gene promoter (CF2-as, bottom middle). In the ventralized mutants grk (top right) and top (middle right), the patch lacking CF2 expression is absent. Similar restoration of CF2 expression can be obtained by inducing two copies of the hsp 70-CF2 transgene (bottom right); in this case CF2 protein is also detectable in the normally unstained border cells and the squamous follicle cells associated with the nurse cells (anterior).

Conversely, when four copies of the CF2-as construct were induced by heat shock, phenocopies were observed resembling moderately although not extremely dorsalized mutants (like spir but not K10 in Fig. 3). The egg chambers assumed a more rounded shape with enlarged and fused appendages and reduced follicle cell counts (Fig. 3; Table 1).
To establish at what stage heat-induced changes in CF2 expression trigger phenocopies, we examined eggs laid at different times after a pulsed heat shock. Using an oogenesis time scale (Spradling 1993), we could infer from the time delay at what stages of oogenesis the analyzed eggs had been exposed to CF2-s or CF2-as action. The data are shown in Figure 4. Both dorsalized and ven-

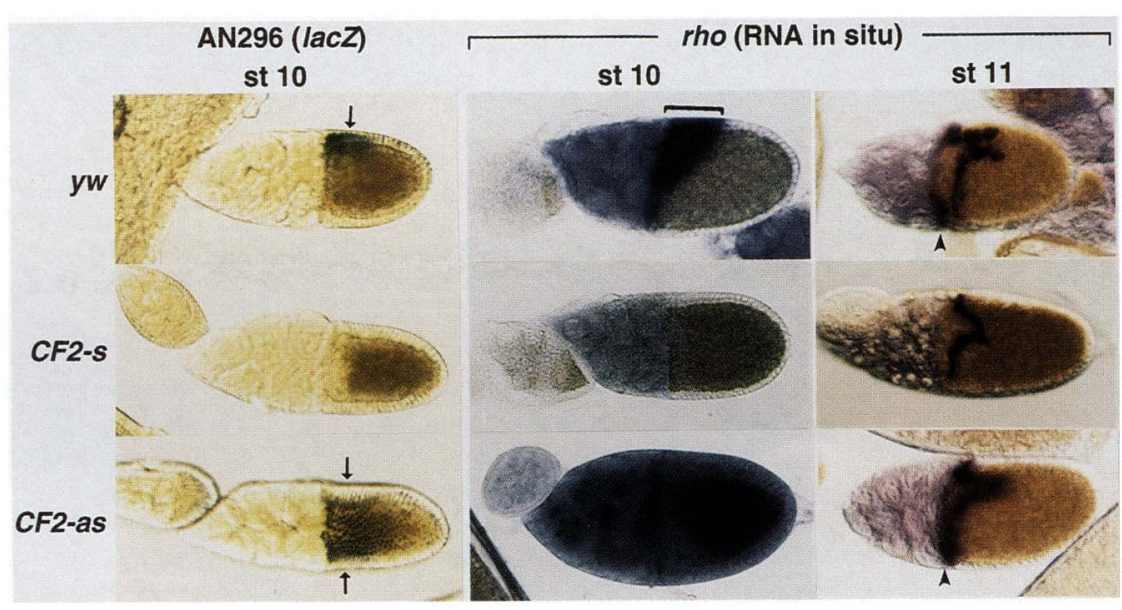

Figure 2. CF2 negatively regulates dorsal follicle cell-specific genes. Ovaries were dissected from well-conditioned females $1.5 \mathrm{hr}$ after completion of pulse heat treatment and were immediately processed for $\mathrm{X}$-gal staining or RNA hybridization. (Left column) Lateral views of X-gal stained stage 10 egg chambers from the enhancer trap line AN296 in the three genetic backgrounds indicated at left. Expression of the lacZ marker directed by AN296 is indicated by arrows. Note the complete elimination of AN296 expression in CF2-s and its ventral expansion in CF2-as. The other columns show dorsal or dorso-lateral views of egg chambers of the same three genotypes, in situ hybridized for rho RNA; two oogenic stages, 10 and 11 , are shown (indicated at top $\mid$. The area of wild-type stage 10 rho expression in the oocyte-associated follicle cell layer is marked by a bracket. At stage 10 (middle column), ectopic CF2 (CF2-s) represses rho expression, whereas antisense RNA (CF2-as) results in ectopic rho expression throughout the egg chamber. At stage 11 (right column), the double stripe element of rho expression on the dorsal surface is not affected by CF2-s or CF2-as, but expression in a thin anterior layer of follicle cells bordering the nurse cells and the oocyte (arrowheads) is repressed in CF2-s. 

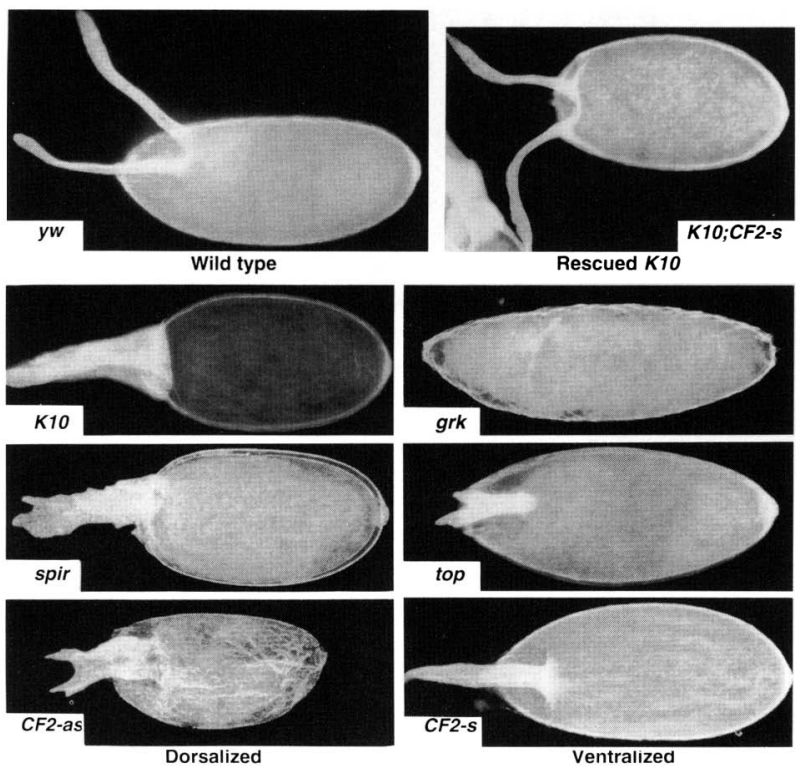

Figure 3. Altered expression of CF2 induces dorsoventral pattern defects in the eggshell. Well-conditioned $y w, C F 2$-as, CF2$s$, and $K 10$; CF2-s flies were exposed to the high-level heat treatment and ovaries were dissected $18 \mathrm{hr}$ later. The K10, spir, grk, and top flies were not heat treated. The wild-type egg chamber (top left) was isolated from a yw female, the parental strain of the transgenic lines. The rest of the left column shows dorsalized phenotypes, which are most extreme in K10. The dorsalized phenotype resulting from CF2-as induction resembles that found in spir. Egg chambers from induced CF2-s flies show moderate ventralized phenotypes comparable to those of top but not as extreme as in grk mutant egg chambers (right column). (Top right) A rescued, nearly wild-type egg from the high-level heattreated $K 10 ; C F 2-s$ flies. Anterior of the eggs are to the left.

tralized phenocopies first appeared at 10-14 hr and peaked $(69 \%-77 \%)$ at $14-19 \mathrm{hr}$ after heat shock. Thus, the presence or absence of CF2 is of maximal importance at about stage 9 to early stage 10, when the EGF-R pathway is activated (Neuman-Silberberg and Schüpbach 1993), and becomes irrelevant shortly thereafter.

Table 1. Comparison of follicle cell counts

\begin{tabular}{lcc}
\hline Phenotype & Genotype & $\begin{array}{l}\text { Number of follicle cell inprints/ } \\
\text { lateral surface }\end{array}$ \\
\hline Wild type & $y w$ & 196 \\
Dorsalized & K10 & 149 \\
& spirc & 167 \\
Ventralized & CF2-as & 159 \\
& grk & 251 \\
& top & 235 \\
& CF2-s & 228 \\
\hline
\end{tabular}

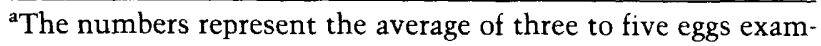
ined from each genotype. Errors are all within $8 \%$.

${ }^{b}$ Follicle cell imprints on one lateral face were counted. Because of the curvature of the egg, one visible lateral face constitutes less than half of the egg surface.

${ }^{c}$ Only those eggs resembling the one in Fig. 3 were examined. They represent moderately dorsalized eggs.
Mosaic analysis suggests that loss of CF2 can lead
to overproduction of dorsal appendage material

We have used mitotic clone analysis to obtain independent genetic evidence suggesting that CF2 depletion may promote a specific dorsal cell fate, at least in anterior dorsal follicle cells that are exposed to EGF-R signaling. Point mutants of CF2 are not currently available. However, $D f(2 \mathrm{~L}) \gamma^{27}$ is a small $(\sim 25 \mathrm{~kb})$ deletion, null for CF2, which removes the entire CF2-coding region and DNA 5' to it (J. Tower, pers. comm.; C. Bagni, S. Bolshakov, and C. Mollinari, unpubl.). Although we cannot exclude the possibility that genes outside the limits of the deficiency might also be affected, no ovarian transcripts other than CF2 have been detected using as probe DNA that is encompassed by this deficiency (data not shown).

Rare defects that apparently represent clonal expansion of a specific type of dorsal fate were observed in eggs

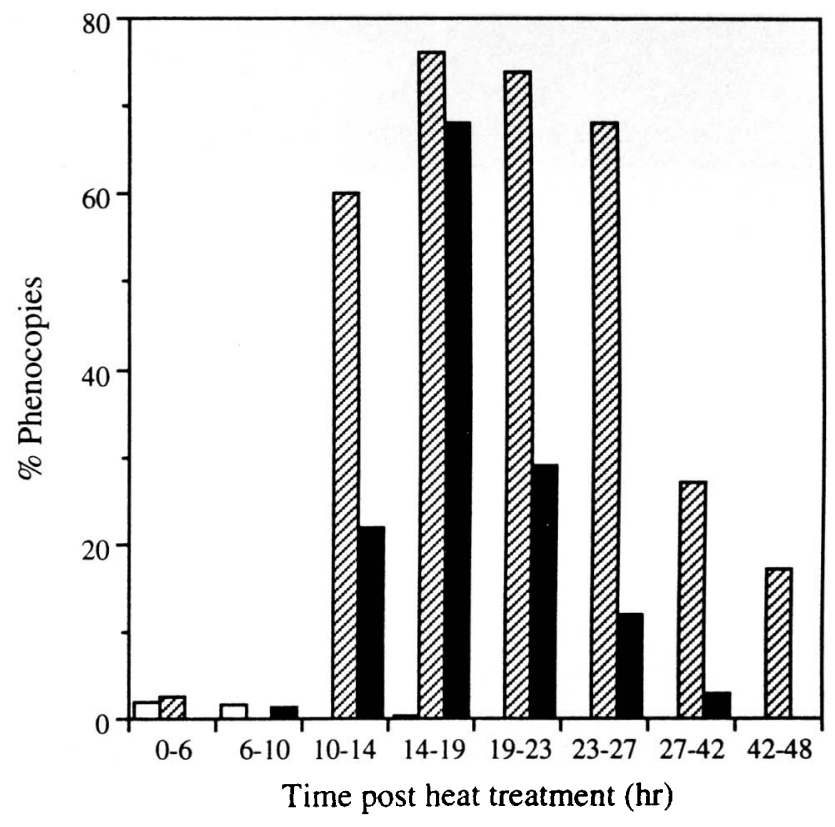

s14-11, s10b, s10a, s10a-9, s9-8, s8, s7-6, s5

Stage at heat shock

Figure 4. Temporal specificity of CF2 phenocopies induced by CF2 misexpression. Well-conditioned flies were pulse heatshocked for $30 \mathrm{~min}$ at $38-39^{\circ} \mathrm{C}$, and laid eggs were collected at different times after completion of the heat treatment. The time of egg collection after heat treatment can be approximately converted to the oogenesis stage at the time of heat shock (according to the scale in Spradling 1993; see text). The eggshell mutant phenocopies are dorsalized and ventralized (as shown in Fig. 3) for CF2-as and CF2-s, respectively. The $0 \mathrm{hr}$ mark denotes the time when heat treatment $(0.5 \mathrm{hr}$ heat-shock $+0.5 \mathrm{hr}$ recovery) was completed. Data shown are the average of three independent experiments for each genotype indicated. Errors are all within $6 \%$. Within $\sim 8 \mathrm{hr}$ after heat treatment a small percentage $(<2 \%)$ of $y w$ egg chambers (open bar) showed slightly fused dorsal appendages, but this was not observed at later times when the CF2-s (hatched bars) and CF2-as (solid bars) phenocopies were observed. 
laid by deficiency heterozygotes that had been X-irradiated either as adults $(8 / 5000 ; 0.16 \%)$ or as first instar larvae $(60 / 6700 ; 0.9 \%)$. These defects were never observed in identically irradiated yw controls. Although the chromosomes were not marked, homozygous clones resulting from $\mathrm{X}$-ray-induced mitotic recombination can be expected at similar frequencies (Wieschaus and Gehring 1976; Stevens et al. 1990). Scanning electron micrographs of these defects are shown in Figure 5 . In the normal chorion (Fig. 5A; Margaritis et al. 1980), the anterior dorsal domain bears two prominent and separate respiratory appendages, smooth near their base and fenestrated more distally to form a respiratory plastron (Spradling 1993). The rest of the chorion surface is marked with polygonal imprints of secretory follicular cells, which are seen in greater relief between the two appendages and in the extreme anterior operculum. Defects seen after X-irradiation of deficiency heterozygotes involve a substantial excess of smooth material resembling the base of the dorsal appendages. This material can replace the various kinds of cell imprints in the operculum, between the appendages or in large sectors of the main body; often it follows polygonal borders, suggestive of clonal origin (Fig. 5E). In other cases, the extra material forms multiple knob-like protrusions (Fig. 5C,D) or even short supernumerary appendages (Fig. 5B). Fenestrated plastron-like surfaces appear ectopically (Fig. 5F).

\section{CF2 can also direct embryonic D/V patterning through a maternal effect}

Having shown that changes in the level of CF2 during oogenesis can alter the $\mathrm{D} / \mathrm{V}$ pattern of the egg chamber, we examined whether it may similarly affect the D/V polarity of the developing embryo. At 14-19 hr after CF2-s induction, flies laid a significant number $(46 \%)$ of eggs that developed into nonviable embryos showing a severely ventralized phenotype with expanded ventral denticles; the phenotype was similar to that of top mutants (Fig. 6A, cf. top and CF2-s). In contrast, similar treatment of CF2-as flies resulted in a significant number $(29 \%)$ of dorsalized embryos that essentially lacked ventral denticles but showed a characteristic "twist" in the anterior cuticle; they resembled mutant embryos laid by $K 10$ females, except that in $K 10$ the posterior segment is often ventralized (Roth and Schüpbach 1994), whereas CF2-as induces dorsalization throughout the ventral epidermis (Fig. 6A, cf. K10 and CF2-as). Because the eggs were laid $14-19 \mathrm{hr}$ after fly heat treatment, the embryonic phenocopies resulted from maternal misex-
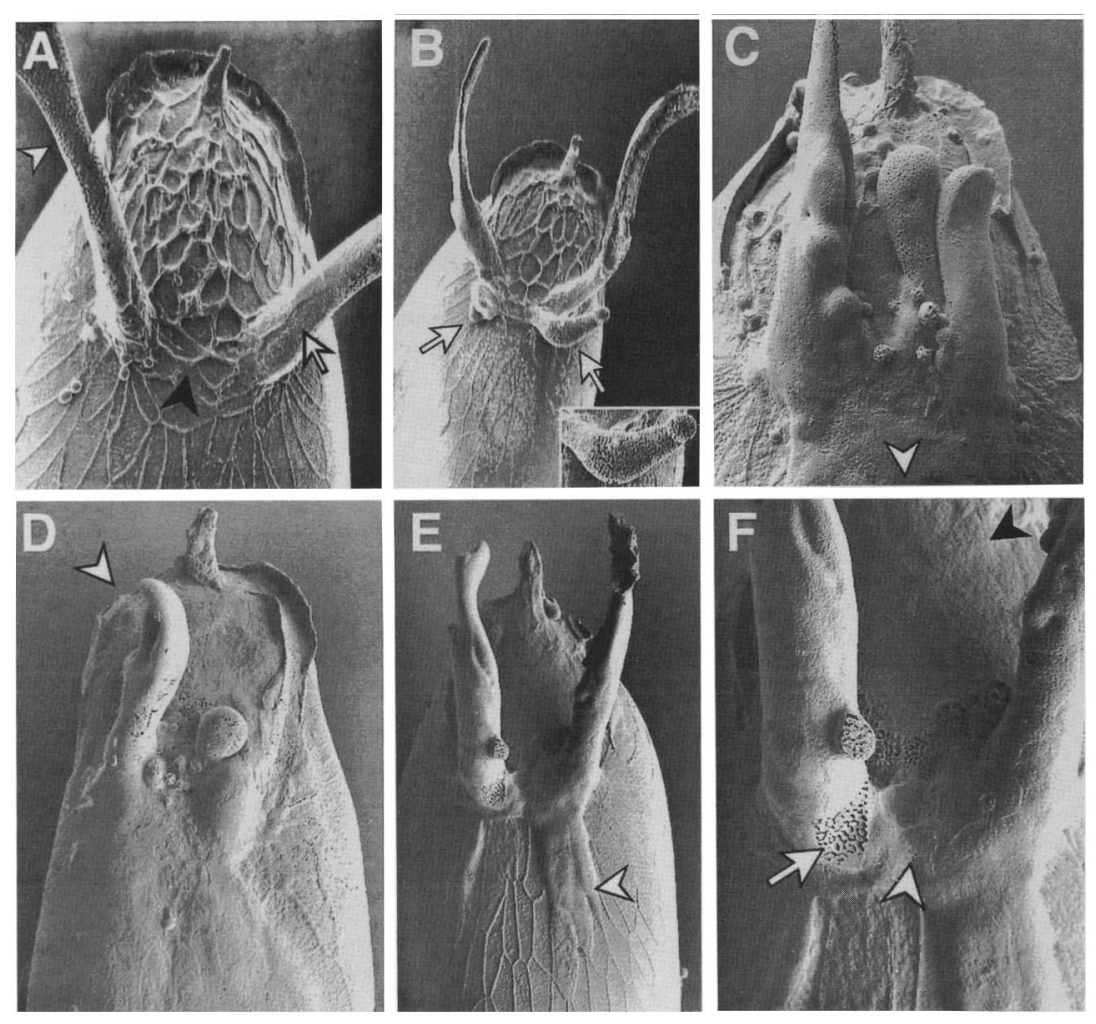

Figure 5. X-ray-induced mitotic clones of $D f(2 L) \gamma^{27}$ cause an expansion of dorsal follicle cell fate. The chorion surfaces of laid eggs were examined by scanning electron microscopy; the anterior end is at the top. First-instar larvae, heterozygous for the $C F 2$ null $D f(2 L) \gamma^{27}$ deletion, were irradiated and the resulting adult females produced some defective eggs as shown. (A) A wild-type egg exhibits clear separation of the two dorsal respiratory appendages (solid arrowhead), each consisting of a smooth shaft (arrow) and a more distal fenestrated plastron (open arrowhead). Also note the follicle cell imprints in the chorion, which are most prominent between the appendages and in the anterior operculum cap, the pointed micropyle and the horse-shoeshaped curved collar. $(B)$ Two short supernumerary appendages (arrows), presumably arising from small clones of cells at the base of the normal appendages. The surrounding follicle cell imprints are normal. The right outgrowth has a plastron-like surface (inset). (C) An extensive area is covered by smooth dorsal material that resembles the shaft of the dorsal appendages, interspersed with plastron-like structures. Note the knob-like bumps and protrusions, and the posterior extension (arrowhead) of this putative clone. $(D)$ An even larger clone affecting most of the left side of the egg has caused a partial loss of the collar (arrowhead) and deposition of thick dorsal material covering the operculum. Interestingly, a second collar-like structure is evident on the right. $|E|$ The expansion of dorsal fate appears clonal. The thick smooth material follows exactly the polygonal cell outlines left by the follicle cells (arrowhead). In a closeup of the same egg $(F)$, smooth dorsal material replaces the normally prominent cell imprints between the appendages (open arrowhead) and on the operculum (closed arrowhead). A few cell imprints showing plastron-like material are evident (arrow). 
Figure 6. Altered expression of CF2 affects dorsoventral patterning in the embryo. $(A)$ Cuticular phenotypes. yw (wild type), CF2-as, CF2-s, and $K 10 ; C F 2-s$ flies were heat treated at the high level as for Fig. 3, and eggs were collected at 14-19 hr later and incubated at $25^{\circ} \mathrm{C}$ for an additional $36 \mathrm{hr}$. For $\mathrm{K} 10$ and top mutants, eggs were collected without heat treatment for $5 \mathrm{hr}$ and incubated at $25^{\circ} \mathrm{C}$ for $36 \mathrm{hr}$. Unhatched embryos were hand-picked and cuticle preparations were made, except for the wild-type cuticle that was made from a newly hatched embryo of yw parents. Anterior is to the left. $(\mathbf{f k}\rangle$ filzkörper; (ve) ventral cuticle; arrowheads point to the anterior constriction in dorsalized embryos. $(B) \mathrm{Al}$ tered expression of dorsoventral marker genes. The yw, CF2-s, and CF2-as flies were heat treated, and eggs were collected and incubated further as above. The RNA detection probes used are indicated at the top, and the fly strains are indicated at the left. Embryos at the blastoderm stage are shown. Anterior is to the left and dorsal side is at top.
A
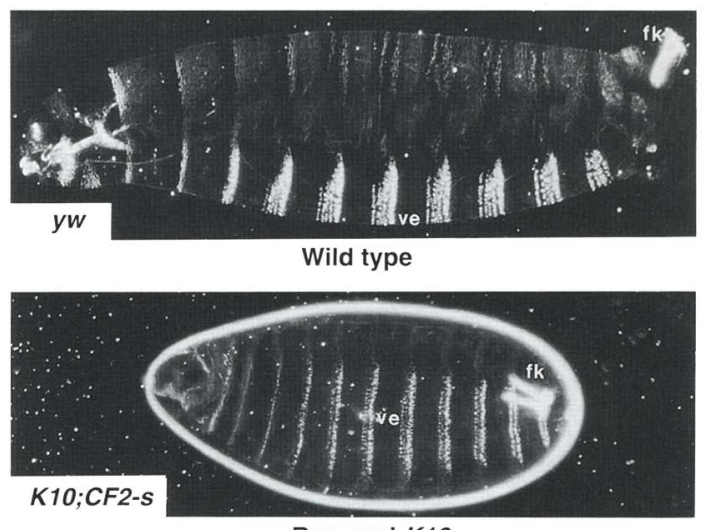

Rescued K10
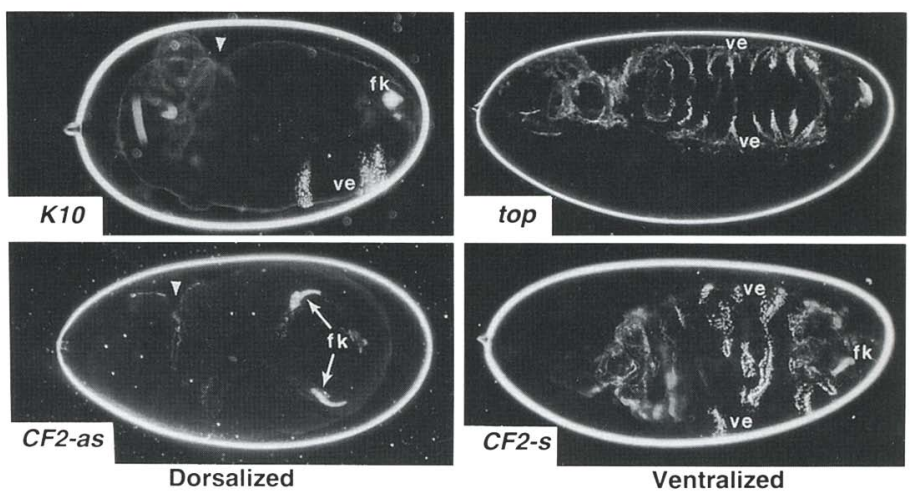

B

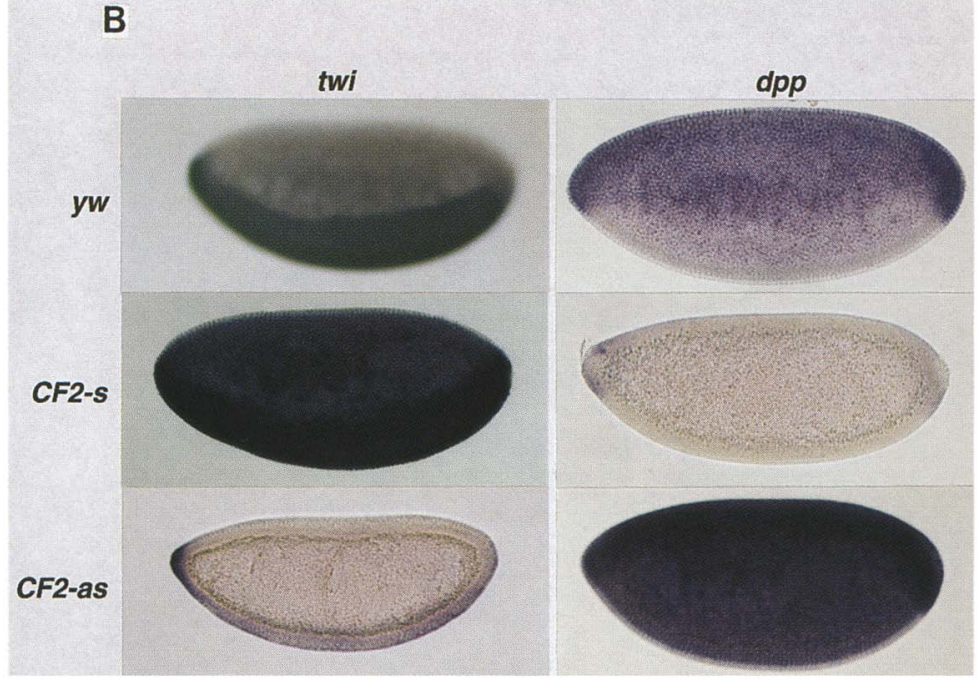

pression of CF2 at stages 9-10a of oogenesis. These phenocopies were not observed in the progeny of heatshocked wild-type flies or of transformants that were not heat-shocked (data not shown).

At comparable frequencies, defects were seen in the expression of $d p p$ and $t w i$ (dorsal and ventral markers, respectively; St. Johnston and Gelbart 1987; Thisse et al. 1988 ) in embryos laid by heat-shocked flies with altered levels of CF2 (Fig. 6B). Follicular expression of the CF2as construct led to molecular dorsalization of $\leqslant 26 \%$ of the embryos; the affected blastoderms showed generalized expression of $d p p$, superimposed on the normal dor- sal expression, and essentially complete lack of expression of the ventral marker twi. In contrast, expression of CF2-s essentially abolished $d p p$ expression and led to generalized twi expression, superimposed on the normal ventral domain of $t w i$ in $\leqslant 36 \%$ of the embryos.

\section{Ectopic expression of CF2 counteracts the dorsalizing effects of $\mathrm{K} 10$ mutants}

Dorsalizing mutations such as $K 10$ spread the negative CF2 patch toward the ventral side of the follicular cell layer (see Fig. 1). An important test of the hypothesis 
that CF2 is functionally downstream of these genes is that the effects of CF2 misexpression should be epistatic; overexpression of CF2 in $\mathrm{K} 10$ backgrounds should counteract the dorsalized chorion and embryonic phenotypes. We confirmed by immunostaining that, as in the wildtype, heat shock induces the CF2-s transgene to produce CF2 throughout the $K 10$ follicular epithelium (data not shown).

$\mathrm{CF} 2$ overexpression can reduce the dorsalizing effects of $K 10$, rescuing $\sim 10 \%$ of the egg chambers (10 of 103 examined), to the point that they showed two distinct rather than fused appendages (see Fig. 3, rescued $\mathrm{K} 10$ ). Similarly, CF2 overexpression during oogenesis can reverse the maternal dorsalizing effect of the $K 10$ mutant on embryonic development (Fig. 6A, rescued K10). About $12 \%$ of the embryos (12 of 98 ) derived from K10; CF2-s had the ventral denticles restored extensively, yielding a phenotype outside the range normally observed in embryos from $\mathrm{K} 10$ mothers. Similar rescues were observed with the weaker dorsalizing mutant spir ${ }^{\mathrm{RP} 48}$.

\section{Ectopic expression of CF2 exacerbates \\ heterozygous top mutant phenotypes}

Contrary to the partial rescue of dorsalized phenotypes, ectopic expression of CF2 is expected to exacerbate ventralizing mutants such as top. This is best illustrated in the heterozygous top background, which produces largely wild-type egg chambers with only $2 \%$ ventralized. As shown in Table 2, a mild heat treatment 3 days at $30^{\circ} \mathrm{C}$ of heterozygous top flies has no phenotypic effect, but in the presence of CF2-s (top/SM6; CF2-s) it generates $43.4 \%$ ventralized eggs, a percentage that is also significantly higher than $C F 2$-s alone $(31.6 \%)$. With more intense heat treatment $130^{\circ} \mathrm{C}$ for 3 days plus two incubations at $37^{\circ} \mathrm{C}$ for $15 \mathrm{~min}$ daily), the frequency of ventralized eggs in top/SM6 alone remains very low (3\%), but in top/SM6; CF2-s it reaches $100 \%$, a severity the same as in homozygous top and again significantly higher than CF2-s alone $(81.8 \%)$.

\section{Discussion}

\section{CF2 as a component of the D/V patterning pathway}

We have presented evidence that in the aggregate, strongly implicates CF2 in D/V patterning during oogenesis. Our interpretation is that CF2 is one of probably several transcription factors that act in concert, within specific domains of the follicular epithelium and in response to the EGF-R tyrosine kinase (RTK) signaling pathway, to pattern the epithelium and the eggshell that it produces, and indirectly to define the $\mathrm{D} / \mathrm{V}$ axis of the embryo. The evidence is as follows:

1. CF2 protein expression is down-regulated in the critical anterodorsal domain (patch) of the epithelium, where the dorsal signal is received. Suppression of CF2 begins around the time that the signal emanates from the oocyte, at stage 9-10.

2. Suppression of CF2 is under the control of the genetic hierarchy that establishes the dorsal and ventral fol-
Table 2: Overexpression of CF2 exacerbates the heterozygous top mutant

\begin{tabular}{lccc}
\hline & \multicolumn{3}{c}{ Percent ventralized eggs } \\
\cline { 2 - 4 } Genotypes $^{\mathrm{a}}$ & $25^{\circ} \mathrm{C}$ & $30^{\circ} \mathrm{C}$ & $30^{\circ} \mathrm{C}+37^{\circ} \mathrm{C}^{\mathrm{c}}$ \\
\hline yw & 0 & 0.5 & 1 \\
top/top & 100 & 100 & 100 \\
top/SM6 & 2 & 2 & 3 \\
CF2-S & 1 & 31.6 & 81.8 \\
top/SM6;CF2-S & 3.5 & 43.4 & 100 \\
\hline
\end{tabular}

${ }^{a}$ All fly strains carry yw markers.

bYoung female flies conditioned previously for 3-4 days at $25^{\circ} \mathrm{C}$ were dissected for ovaries after a 3-day incubation period at the designated temperatures. $30^{\circ} \mathrm{C}+37^{\circ} \mathrm{C}$ denotes additional heat shock of $15 \mathrm{~min}$ twice daily at $37^{\circ} \mathrm{C}$ in a 3 -day $30^{\circ} \mathrm{C}$ incubation period.

${ }^{c}$ In each condition, ovaries were dissected at the end of incubation, and 200-250 stage 14 eggs were scored.

licular cell fates. In particular, it is responsive to the maternal-effect genes $K 10$, spir, grk, and top.

3. CF2 itself can alter D/V patterning. In particular, ectopic depletion of CF2 spatially expands the expression of the dorsal gene markers AN296 and rho. Conversely, ubiquitous CF2 overexpression (presumably the persistence of CF2 in the anterodorsal follicular cell patch) has the opposite effect, blocking the expression of these dorsal genes.

4. Significantly, CF2 depletion and CF2 overexpression produce opposite effects, which resemble partial dorsalization and ventralization of the anterior chorion, respectively. Moreover, changes in CF2 during oogenesis have long-term effects; depletion or overexpression result in dorsalization or ventralization of the embryo, respectively, subsequent to fertilization, according to both cuticular and molecular markers.

5. Specific and spectacular effects on chorion structure are observed by $\mathrm{X}$-irradiation of flies heterozygous for a small deficiency, null for CF2. The defects are localized, with irregular borders that follow cell imprint borders, and apparently correspond to overexpression of dorsal appendage material, sometimes in large sectors that can encompass the operculum and major parts of the main body; often they result in formation of extra appendages or appendage-like knobs.

6. CF2 overexpressed during oogenesis dramatically counteracts the dorsalizing effects of the K10 mutant, both on the follicular chorion product and on the postfertilization embryo. Conversely, CF2 overexpression exacerbates a top heterozygote, which by itself produces wild-type chorions. Thus, CF2 is downstream of the well-known determinants of $\mathrm{D} / \mathrm{V}$ polarity, K10, and top.

We have not demonstrated rigorously that the observed effects are somatic (follicular) cell specific, rather than mediated by the germ-line cells (nurse cells and oocyte). However, this conclusion is supported by the evident EGF-R-controlled patterns of CF2 expression in 
the follicular cell, by our inability to detect CF2 in the oocyte even upon CF2-s induction, and by the lack of immunostainable CF2 in embryos earlier than stage 13 ( 9 hr; C. Bagni, J.A. Gogos, S. Bray, and F.C. Kafatos, in prep.). The observed $\mathrm{D} / \mathrm{V}$ defects resulting from changes in CF2 levels were described as pattern dorsalization and ventralization; they resemble the defects associated with weak to moderate mutations high on the $\mathrm{D} / \mathrm{V}$ hierarchy but are not as extreme as those associated with the strongest alleles of $K 10$ and grk. This might be expected for heat shock-driven constructs, especially for antisense constructs that are often only partially effective. On the other hand, some differences appear to be more than quantitative, suggesting that CF2 is only one of several transcription factors mediating the effects of the EGF-R signaling pathway, and is somewhat specialized in its effects.

\section{The mechanism of CF2 action in D/V patterning}

On the basis of our results and previous information, we present in Figure 7 a plausible model for CF2 action.

From the mutant phenotypes and the fact that immunostainable CF2 begins to disappear from the anterodorsal patch at late stage 9, before rho RNA appears in the same cells at early stage 10 , we infer that activation of EGF-R by Gurken binding clears away CF2 through a mechanism that initially does not require $r h o$. This is consistent with the observation that initially the overexpressed CF2 acts upstream of rho, to repress the early rho expression pattern. In the normal course of events, suppression of CF2 permits expression of rho, AN296, and other aspects of the dorsal cell fate, including formation of normal dorsal appendages. However, we do not know yet whether the apparent repressor function of CF2 is direct or indirect.

We have not investigated the steps between activation of EGF-R and suppression of CF2. However, from previous studies on ovarian patterning we know that activated EGF-R and Rho act in concert to set in train a signal transduction cascade that includes the Ras, Raf, and MAPK kinase (MEK) protein kinases (Ruohola-Baker et al. 1993; Brand and Perrimon 1994; Hsu and Perrimon 1994; Lu et al. 1994). This cascade may also include MEK-activated mitogen-activated protein kinase (MAPK), which is known to translocate into the nucleus and phosphorylate diverse transcription factors in vertebrates and certain Drosophila tissues (Sturtevant et al. 1993; Karin 1994; Dickson 1995). In the Drosophila eye, Drosophila MAPK is capable of oppositely modulating the activities of two Ets-related factors, enhancing the Pointed activator (Brunner et al. 1994) and suppressing the Yan repressor (Rebay and Rubin 1995). In the latter case, MEK-activated MAPK phosphorylates Yan and thereby causes Yan to translocate back to the cytoplasm where it is rapidly subject to degradation, apparently elicited by carboxy-terminal PEST sequences (Rebay and Rubin 1995). We propose a similar explanation for the loss of CF2 where and when the kinase cascade is triggered by activation of EGF-R in the follicle cells. Interestingly, the CF2 amino acid sequence (Hsu et al. 1992)

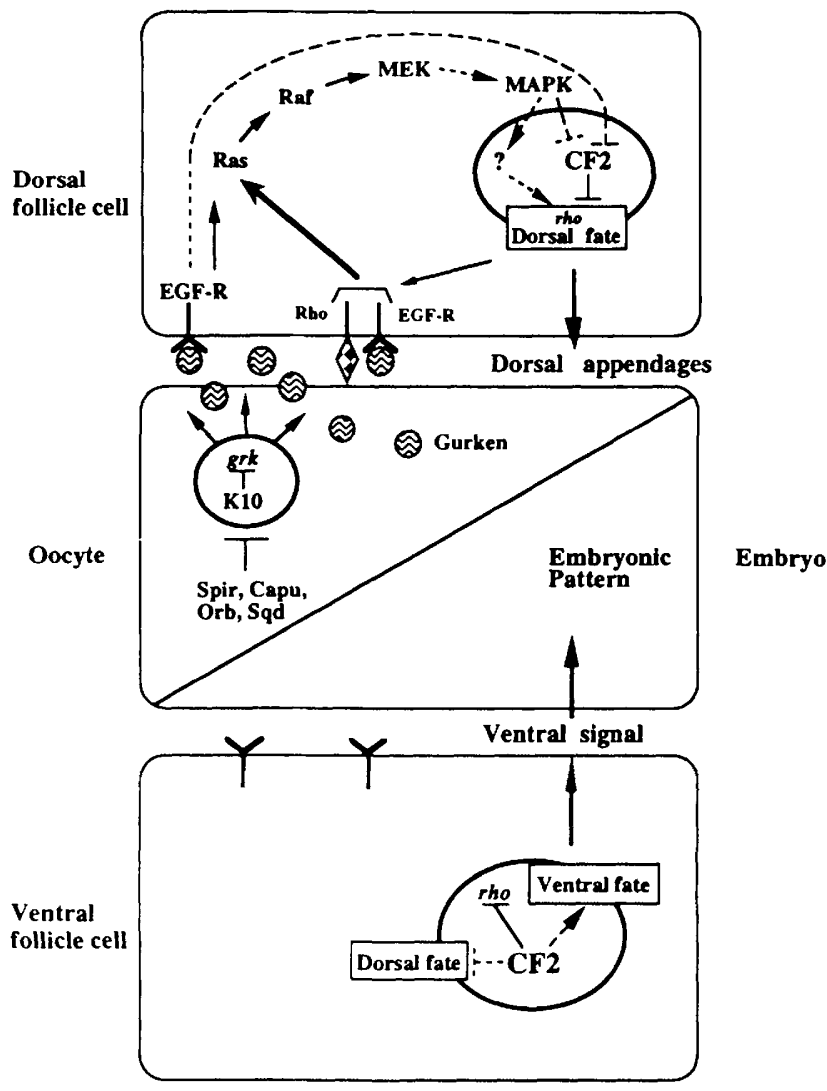

Figure 7. A model of dorsoventral patterning and the role of CF2. Patterning processes are diagrammed in three domains: anterior dorsal (top) and ventral (bottom) follicle cells, and oocyte/embryo (middle). Known steps are shown by solid arrows (activation) or bars (inhibition). Broken lines indicate hypothetical or alternative processes; circles indicate the nucleus. Suppression of CF2 is most likely to occur through MAPK, but we cannot exclude other possibilities (long curved broken line from EGF-R/. In this model, CF2 acts as repressor of rho expression and the dorsal cell fates. We also suggest that other positive transcription regulators may be regulated by MAPK, by analogy with MAPK action in other systems. Directly or indirectly, CF2 represses rho and dorsal fates but activates ventral fates. For details, see text.

shows three PEST-like motifs (Rogers et al. 1986) in the middle region and, near the amino terminus, a putative site for phosphorylation by MAPK. We have observed that while CF2 disappears its RNA persists /data not shown), implying some post-transcriptional mechanism for CF2 clearance; we suggest a post-translational explanation, although we cannot exclude a translational mechanism.

Once initiated, the EGF-R cascade may operate as a loop, as it affects CF2 and CF2 affects rho, which in turn is known to affect but also to depend on EGF-R function (Ruohola-Baker et al. 1993). Loop function could amplify the dorsal signal (Sturtevant et al. 1993) and reinforce the assignment of dorsal cell fates. Initial transduction of the Grk signal occurs in the absence of Rho but may feed into the same pathway, initiating the loop (Fig. 7).

Our results indicate that CF2 functionally activates 
ventral cell fates. We do not know whether it does so as a direct activator of ventral genes, as an indirect activator (e.g., through a double-repressor mechanism), or by default as a result of repression of dorsal genes. In any case, the influence of CF2 is propagated into the embryo, affecting the embryonic D/V pattern (Fig. 7).

Earlier Grk/EGF-R signaling is now known to specify posterior polar follicle cell fates, thus initiating anteriorposterior axis determination (Gonzales-Reyes et al. 1995; Roth et al. 1995). As in the case of Rho (RuoholaBaker et al. 1993), CF2 does not seem to participate in this earlier patterning process; there is no evident suppression of CF2 in the posterior polar follicle cells (Fig. 1), and no anterior-posterior patterning defects have been observed upon CF2 misexpression (T. Hsu, unpubl.).

\section{CF2 and subpopulations of the follicular epithelium}

Follicular patterning involves not only the distinction between anterodorsal and ventral cells but the establishment of multiple, spatially distinct subpopulations of the follicular epithelium (Margaritis et al. 1980; Tolias and Kafatos 1990; for review, see Spradling 1993). We note that the anterior-most border cells and the squamous cells associated with the nurse cell cap are devoid of CF2, in the wild type as well as in dorsalized and ventralized mutants (Fig. 1; data not shown); these cells do not express the AN296 enhancer trap marker (Fig. 2), despite the absence of CF2. Similarly, the cells that correspond to the two different elements of the rho expression pattern at stage 11 show different temporal susceptibilities to CF2. Evidently, unknown features of follicular cell differentiation delimit to specially competent subpopulations the ability to receive and respond to the EGF-R activation signal by loss of CF2 and expression of specific dorsal fates. At present, our results are consistent with CF2 having its major role at the earliest stage of $\mathrm{D} / \mathrm{V}$ patterning, in a circumferential band of columnar follicle cells that surround the anterior portion of the oocyte. This band is divided in the wild type into $C F 2^{-}$ and $\mathrm{CF}^{+}{ }^{+}$sectors, as a result of EGF-R signaling; in dorsalized mutants the band is visualized because of the circumferential lack of CF2 (Fig. 1). Future work using CF2 mutants and mitotic clone analysis might help illuminate the spatial domains and temporal dynamics of $\mathrm{D} / \mathrm{V}$ patterning, and the roles of the CF2 transcription factor in specific aspects of this process.

\section{Materials and methods}

Drosophila strains

Genotypes of mutants (kindly provided by T. Schüpbach, Princeton University, NI, and W.M. Gelbart, Harvard University, Cambridge, MA) used in this study were as follows: (1) pr, cn, top ${ }^{Q Y 1}, b w / C y O ;(2) f_{s}(1) K 10^{1}, w, f / F M 3 ;\left\{3 \mid b, p r\right.$, spir ${ }^{R P 48}$, $b w / C y O$; and $(4) g^{\prime} k^{H K 36}, \mathrm{cn}, \mathrm{bw}, \mathrm{Elp} / \mathrm{CyO}$. AN296 is an enhancer trap/lacZ strain described by Bier et al. (1989), kindly provided by $\mathrm{T}$. Schüpbach. The fly strains $f_{S}(1) K 10^{1}, w, f / F M 3$; $P / w^{+}$, hsp70-CF2] (K10/CF2-s for short) and $y, w ; p r, c n$, top ${ }^{Q Y 1}, b w / S M 6 a ; P / w^{+}$, hsp 70-CF2) (top/SM6; CF2-s for short) were obtained by standard crosses.

\section{Transgenic lines}

For CF2 overexpression experiments, CF2-s transgenic lines were created using a 2-kb EagI-Clal fragment of the ovarian CF2 cDNA (Gogos et al. 1992; Hsu et al. 1992) containing 119 bp of the 5 '-untranslated region (UTR), the entire coding region, and 429 bp of the 3' UTR. This fragment was cloned into the Hpal site of the pCaSpeR-hs vector (Pirrotta 1988) in the forward orientation downstream of the $h s p 70$ gene promoter. For CF2 depletion experiments CF2-as lines were created using an 887 bp HindIII (from the plasmid vector-NarI fragment derived from a partial ovarian CF2 cDNA clone (Gogos et al. 1992; Hsu et al. 19921, containing $247 \mathrm{bp}$ of the $5^{\prime}$ UTR and $640 \mathrm{bp}$ of the $5^{\prime}$ portion of the coding region. This fragment was cloned into the HpaI site of the pCaSpeR-hs vector in the reversed orientation. Germ-line transformations in the $y w$ strain were performed by standard procedures (Spradling 1986). Five CF2-s homozygous lines were generated that exhibited similar phenotypes upon heat treatment; the data reported came from line T3, bearing the insert on the third chromosome. Three CF2-as homozygous lines were obtained and crossed to generate two doubly homozygous lines; we show data from line asl;aTl, with inserts in both autosomes.

\section{Heat treatment}

Newly hatched females were conditioned (with half the number of males) in the presence of live yeast at room temperature for 4 days. Three types of heat shock regimens were used: (1) low level: 3 -day incubation at $30^{\circ} \mathrm{C} ;(2)$ high level: 3 -day incubation at $30^{\circ} \mathrm{C}$ plus two 15 -min incubations at $37^{\circ} \mathrm{C}$ daily (e.g., at 9 a.m. and 7 p.m.); (3) pulsed heat shock: flies were transferred to a prewarmed bottle containing media and incubated at $38-39^{\circ} \mathrm{C}$ for $30 \mathrm{~min}$, after which the bottles were transferred to $25^{\circ} \mathrm{C}$ and incubated for $30 \mathrm{~min}$. We determined that if no further disturbance (such as anesthesia) was applied at this point, the flies would resume egg laying. The entire heat shock and recovery regimen is referred to as heat treatment. After heat treatment, the flies were either transferred to fresh bottles of media, incubated at $25^{\circ} \mathrm{C}$, and dissected at different times for examination of ovaries, or were transferred to cages for egg collection and scoring of embryos as described (Roberts 1986).

\section{Mosaic analysis}

The strain $D f(2 \mathrm{~L}) \gamma^{27} \mathrm{cn} / \mathrm{CyO} ; \mathrm{ry}^{506}$, a kind gift of J. Tower (University of Southern California, Los Angeles) was generated by imprecise P-element excision after $\gamma$-irradiation of the homozygous viable starter strain $\left.P / l a c Z, \mathrm{ry}^{+}\right)^{C B 25 A}, \mathrm{cn}$. The original insertion was mapped $5-10 \mathrm{~kb}$ upstream of $\mathrm{CF} 2$, and the resulting deletion removes $\sim 25 \mathrm{~kb}$ (J. Tower, pers. comm.). The deletion results in a larval lethal phenotype and was characterized by in situ hybridization of CF2 genomic clones to polytene chromosomes, genomic PCR, and CF2 antibody staining of homozygous embryos; no CF2 coding region or CF2 protein expression could be detected (C. Bagni, S. Bolshakov, and C. Mollinari, unpubl.). Female $y w /+; D f(2 L) \gamma^{27} \mathrm{cn} /+$ and control yw homozygotes were X-ray-irradiated (1050 R, Torrex 120D source) as first-instar larvae or adults according to the method of Stevens et al. (1990). Eggs were collected on apple juice/agar plates for a period of 3 days, and dorsal appendages were examined. Selected eggs were either critical-point dried or air-dried before sputter-coating and viewed using a Philips XL-30 field emission scanning electron microscope. Images were processed using Adobe Photoshop.

Immunostaining

The CF2 monoclonal antibody was obtained from a mouse hy- 
dridoma (Gogos 1993). Newborn flies were conditioned for 2 days at room temperature. Egg chambers were dissected in Drosophila Ringer's solution (Roberts 1986) and processed in Nitex baskets within 24-well microtiter dishes at room temperature. They were incubated for $8 \mathrm{~min}$ in $4 \%$ methanol-free formaldehyde (from Polyscience) in PBS, washed, and permeabilized for $8 \mathrm{~min}$ in PBS containing $0.1 \%$ Triton X-100. After three washes in PBS, follicles were incubated with CF2 monoclonal antibody for 3-15 hr, washed three times in PBS, and incubated for 1-2 hr with 1:300 dilution of fluorescein (DTAF)-conjugated affinity pure goat anti-mouse $\operatorname{IgG}(\mathrm{H}+\mathrm{L}$ ) (from Jackson ImmunoResearch Laboratories) in PBS, $0.5 \%$ BSA. They were rinsed for $10 \mathrm{~min}$ in PBS and transferred through a series of 20 -min incubations in PBS solutions with increasing concentrations of glycerol: $30 \%, 50 \%$, and $80 \%$ (adjusted to $\mathrm{pH} 7$ ). Whole mounts were prepared by transferring follicles into Gelvatol mounting solution (Harlow and Lane 1988). They were analyzed using a Compact Confocal Microscope (CCM) built at the European Molecular Biology Laboratory (EMBL), Heidelberg, Germany (E. Stelzer and collaborators, Light Microscopy Group)

\section{Detection of $\beta$-galactosidase activity in ovaries}

Ovaries bearing the AN296 enhancer trap insert were dissected in PBS from well-conditioned and pulse heat-shocked females (see above) at $1.5 \mathrm{hr}$ after heat treatment and were fixed for 8 min in $1 \%$ glutaraldehyde (from Sigma) in PBS. They were rinsed three times in PBS $0.5 \%$ Triton-X100, stained at $37^{\circ} \mathrm{C}$ for $30 \mathrm{~min}$ in PBS containing $0.2 \% \mathrm{X}$-gal (from Sigma), $5 \mathrm{~mm}$ $\mathrm{K}_{4}\left[\mathrm{Fe}(\mathrm{III}) \mathrm{CN}_{6}\right], 5 \mathrm{mM} \mathrm{K}_{3}\left[\mathrm{Fe}(\mathrm{II}) \mathrm{CN}_{6}\right], 0.3 \%$ Triton- $\mathrm{X} 100$, rinsed in PBS, and mounted in PBS $90 \%$ glycerol for microscopic analysis.

\section{RNA in situ hybridization}

The hybridization probes used were a $2.5-\mathrm{kb}$ rho cDNA fragment encompassing the entire $1.07-\mathrm{kb}$ coding region (kindly provided by $\mathrm{H}$. Ruohola-Baker, University of Washington, Seattle); a 4.5-kb dpp cDNA from the pNB40 library (St. Johnston et al. 1990); and a 530-bp twi genomic EcoRI-BamHI fragment (Thisse et al. 1988; the $d p p$ - and twi-containing plasmids were kindly provided by W. Gelbart). The probes were labeled with digoxygenin as described by the supplier (Boehringer Mannheim Biochemicals). For rho staining of egg chambers, newly hatched females were conditioned and pulse heat-shocked as described above, kept in the same bottle of media for another $1.5 \mathrm{hr}$ of incubation at $25^{\circ} \mathrm{C}$, and anesthetized on ice; ovaries were dissected in Ringer's solution. For $d p p$ and $t w i$ staining of embryos, well-conditioned young flies (4-5 days old) were heat-shocked at the high level as described, and embryos were collected at 14-18 hr after heat treatment and incubated for another hour at $25^{\circ} \mathrm{C}$ (i.e., collection of $1-5 \mathrm{hr}$ embryos). The staining and detection procedures have been described (Tautz and Pfeifle 1989; Hsu et al. 1993). For examination, ovaries and embryos were mounted in a mixture of Ringer's and glycerol $(1: 1)$ or a mixture of $\mathrm{PBS} / 0.1 \%$ Tween 20 and glycerol $(1: 1)$, respectively.

\section{Cuticle preparations}

Cuticle preparations were made essentially as described (Wieschaus and Nüsslein-Volhard 1986), and photographed by darkfield optics.

\section{Acknowledgments}

We are grateful to Dennis King for the initial observation of CF2 depletion in the anterodorsal patch and for antibody production. We thank Aruna Bhat for technical assistance, Nick Salmon for confocal and Roger Wepf for scanning electron microscopy, $\mathrm{N}$.
Perrimon for communicating unpublished results, Steve Cohen Carl Hashimoto, Marek Mlodzik, Cliff Schweinfest, and Dennis Watson for critical reading of the manuscript, and our laboratory colleagues for stimulating discussions. T.H. was supported by a development grant to Center for Molecular and Structural Biology from the Department of Energy and the Medical University of South Carolina Institutional Research Funds, C.B. was supported by a National Institutes of Health (NIH) Fogarty Fellowship and a Human Capital Mobility (European Union) fellowship, and J.D.S. and F.C.K by an NIH program project grant.

The publication costs of this article were defrayed in part by payment of page charges. This article must therefore be hereby marked "advertisement" in accordance with 18 USC section 1734 solely to indicate this fact.

\section{References}

Bier, E., H. Vaessin, S. Shepherd, K. Lee, K. McCall, S. Barbel, L. Ackerman, R. Carretto, T. Uemura, E. Grell, L.Y. Jan, and Y.N. Jan. 1989. Searching for pattern and mutation in the Drosophila genome with a P-lacZ vector. Genes \& Dev. 3: 1273-1287.

Brand, A.H. and N. Perrimon. 1994. Raf acts downstream of the EGF receptor to determine dorsoventral polarity during Drosophila oogenesis. Genes \& Dev. 8: 629-639.

Brunner, D., N. Oellers, J. Szabad, W.H. Biggs III, S.L. Zipursky, and E. Hafen. 1994. A gain-of-function mutation in Drosophila MAP kinase activates multiple receptor tyrosine $\mathrm{ki}$ nase signaling pathways. Cell 76: 875-888.

Chasan, R. and K.V. Anderson. 1993. Maternal control of dorsalventral polarity and pattern in the embryo. In The development of Drosophila melanogaster (ed. M. Bate and A. Martinez Arias\}, pp. 387-424. Cold Spring Harbor Laboratory Press, Cold Spring Harbor, NY.

Christenson, L.B. and D.M. McKearin. 1994. orb is required for anteroposterior and dorsoventral patterning during Drosophila oogenesis. Genes \& Dev. 8: 614-628.

Dickson, B. 1995. Nuclear factors in sevenless signaling. Trends Genet. 11: 106-111.

Forlani, S., D. Ferrando, O. Saget, and E. Mohier. 1993. A regulatory function for $\mathrm{K} 10$ in the establishment of dorsoventral polarity in the Drosophila egg and embryo. Mech. Dev. 41: 109-120.

Gogos, J.A. 1993. "Zinc fingers: DNA sequence discrimination in development and evolution." Ph. D. thesis. Harvard University, Boston, MA.

Gogos, J.A., T. Hsu, J. Bolton, and F.C. Kafatos. 1992. Sequence discrimination by alternatively spliced isoform of a DNA binding zinc finger domain. Science 257: 1951-1955.

González-Reyes, A., H. Elliott, and D. St. Johnston. 1995. Polarization of both major body axes in Drosophila by gurkentorpedo signaling. Nature 375: 654-658.

Harlow, E. and D. Lane. 1988. Antibodies: A laboratory manual. Cold Spring Harbor Laboratory Press, Cold Spring Harbor, NY.

Hashimoto, C., S. Gettula, and K.V. Anderson. 1991. Plasma membrane localization of the Toll protein in the syncytial Drosophila embryo: Importance of transmembrane signaling for dorsal-ventral pattern formation. Development 111: 1021-1028.

Hsu, I.C. and N. Perrimon. 1994. A temperature-sensitive MEK mutation demonstrates the conservation of the signaling pathways activated by receptor tyrosine kinases. Genes \& Dev. 8: 2176-2187.

Hsu, T., J.A. Gogos, S.A. Kirsh, and F.C. Kafatos. 1992. Multiple zinc finger forms resulting from developmentally regulated 
alternative splicing of a transcription factor gene. Science 257: 1946-1950.

Hsu, T., D.L. King, C. La Bone, and F.C. Kafatos. 1993. A Drosophila single-stranded DNA/RNA-binding factor contains a high-mobility-group box and is enriched in the nucleolus. Proc. Natl. Acad. Sci. 90: 6488-6492.

Jiang, J., D. Kosman, Y.T. Ip, and M. Levine. 1991. The dorsal morphogen gradient regulates mesoderm determinant twist in early Drosophila embryos. Genes \& Dev. 5: 1881-1891.

Karin, M. 1994. Signal transduction from the cell surface to the nucleus through the phosphorylation of transcription factors. Curr. Opin. Cell Biol. 6: 415-424.

Kelly, R.L. 1993. Initial organization of the Drosophila dorsoventral axis depends upon an RNA-binding protein encoded by the squid gene. Genes \& Dev. 7: 948-960.

Lu, X., M.B. Melnick, J.-C. Hsu, and N. Perrimon. 1994. Genetic and molecular analyses of mutations involved in Drosophila raf signal transduction. EMBO J. 13: 2592-2599.

Manseau, L.J. and T. Schüpbach. 1989. cappuccino and spire: Two unique maternal effect loci required for both the anterioposterior and dorsoventral patterns of the Drosophila embryo. Genes \& Dev. 3: 1437-1452.

Margaritis, L.H., F.C. Kafatos, and W.H. Petri. 1980. The eggshell of Drosophila melanogaster. I. Fine structure of the layers and regions of the wild-type eggshell. I. Cell Sci. 43: 135.

Neuman-Silberberg, F.S. and T. Schüpbach. 1993. The Drosophila dorsoventral patterning gene gurken produces a dorsally localized RNA and encodes a TGF $\alpha$-like protein. Cell 75: $165-174$.

Perrimon, N. 1994. Signaling pathways initiated by receptor protein tyrosine kinases in Drosophila. Curr. Opin. Cell. Biol. 6: 260-266.

Pirrotta, V. 1988. Vectors for P-element transformation in Drosophila. In Vectors. A survey of molecular cloning vectors and their uses (ed. R.L. Rodriguez and D.T. Denhardt), pp. 437-456. Butterworths, Boston, MA

Price, J.V., R.J. Clifford, and T. Schüpbach. 1989. The maternal ventralizing locus torpedo is allelic to faint little ball, an embryonic lethal, and encodes the Drosophila EGF receptor homologue. Cell 56: 1085-1092.

Prost, E., F. Derykere, C. Roos, M. Haenlin, V. Pantesco, and E. Mohier. 1988. Role of the oocyte nucleus in determination of the dorsoventral polarity of Drosophila as revealed by molecular analysis of the K10 gene. Genes \& Dev. 2: 891-900.

Rebay, I. and G.M. Rubin. 1995. Yan functions as a general inhibitor of differentiation and is negatively regulated by activation of the Rasl/MAPK pathway. Cell 81: 857-866.

Roberts, D.B. 1986. Basic Drosophila care and techniques. In Drosophila: A practical approach (ed. P.B. Roberts), pp 1-38. IRL Press, Oxford, UK.

Rogers, S., R. Wells, and M. Rechsteiner. 1986. Amino acid sequences common to rapidly degraded proteins: The PEST hypothesis. Science 234: 364-368.

Roth, S. and T. Schüpbach. 1994. The relationship between ovarian and embryonic dorsoventral patterning in Drosophila. Development 120: 2245-2257.

Roth, S., F.S. Newman-Silberberg, G. Barcelo, and T. Schüpbach. 1995. Cornichon and the EGF receptor signaling process are necessary for both anterior-posterior and dorsal-ventral pattern formation in Drosophila. Cell 81: 967-978.

Ruohola-Baker, H., E. Grell, T.-B. Chou, D. Baker, L.Y. Jan, and Y.N. Jan. 1993. Spatially localized rhomboid is required for establishment of the dorsal-ventral axis in Drosophila oogenesis. Cell 73: 953-965.

Ruohola-Baker, H., L.Y. Jan, and Y.N. Jan. 1994. The role of gene cassettes in axis formation during Drosophila oogenesis. Trends Genet. 10: 89-94.

Schneider, D.S., K.L.Hudson, T.-Y. Lin, and K.V. Anderson. 1991. Dominant and recessive mutations define functional domains of Toll, a transmembrane protein required for dorsal-ventral polarity in the Drosophila embryo. Genes \& Dev. 5: 797-807.

Schüpbach, T. 1987. Germ line and soma cooperate during oogenesis to establish the dorsoventral pattern of egg shell and embryo in Drosophila melanogaster. Cell 49: 699-707.

Schüpbach, T. and E. Wieschaus. 1989. Female sterile mutations on the 2nd chromosome of Drosophila. I. Matemal effect mutations. Genetics 121: 101-117.

_- 1991. Female sterile mutations on the second chromosome of Drosophila melanogaster. II. Mutations blocking oogenesis or altering egg morphology. Genetics 129: 1119I 136.

Schüpbach, T., R.J. Clifford, L.J. Manseau, and J.V. Price. 1991. Dorsoventral signaling processes in Drosophila oogenesis. In Cell-cell interactions in early development (ed. J. Gerhart), pp. 163-174. Wiley-Liss, New York, NY.

Shea, M.J., D.L. King, M.J. Conboy, B.D. Mariani, and F.C. Kafatos. 1990. Proteins that bind to Drosophila chorion cis-regulatory elements: A new $\mathrm{C}_{2} \mathrm{H}_{2}$ zinc finger protein and a $\mathrm{C}_{2} \mathrm{C}_{2}$ steroid receptor-like component. Genes \& Dev. 4:11281140 .

Spradling, A. 1986. P element-mediated transformation. In Drosophila, a practical approach (ed. D.B. Roberts), pp. 175198. IRL Press, New York, NY.

1993. Developmental genetics of oogenesis. In The development of Drosophila melanogaster (ed. M. Bate and A. Martinez Arias), pp. 1-70. Cold Spring Harbor Laboratory Press, Cold Spring Harbor, NY.

St. Johnston, R.D., and W.M. Gelbart. 1987. Decapentaplegic transcripts are localized along the dorsal-ventral axis of the Drosophila embryo. EMBO 1. 6: 2785-2791.

St. Johnston, R.D., F.M. Hoffmann, R.K. Blackman, D. Segal, R. Grimaila, R.W. Padgett, H.A. Irick, and W.M. Gelbert. 1990. Molecular organization of the decapentaplegic gene in Drosophila melanogaster. Genes \& Dev. 4: 1114-1127.

Stevens, L.M., H.G. Frohnhöfer, M. Klinger, and C. NüssleinVolhard. 1990. Localized requirement for torso-like expression in follicle cells for development of terminal anlagen of the Drosophila embryo. Nature 346: 660-663.

Sturtevant, M. A., M. Roark, and E. Bier. 1993. The Drosophila rhomboid gene mediates the localized formation of wing veins and interacts genetically with components of the EGF-R signaling pathway. Genes \& Dev. 7: 961-973.

Tautz, D. and C. Pfeifle. 1989. A nonradioactive in situ hybridization method for the localization of specific RNAs in Drosophila embryos reveals a translational control of the segmentation gene hunchback. Chromosoma 98: 81-85.

Thisse, B., C. Stoetzel, C. Gorostizia-Thisse, and F. Perrine Schmitt. 1988. Sequence of the twist gene and nuclear localization of its protein in endomesodermal cells of early Drosophila embryo. EMBO /. 7: 2175-2183.

Tolias, P. and F.C. Kafatos. 1990. Functional dissection of an early Drosophila chorion gene promoter: Expression throughout the follicular epithelium is under spatially composite regulation. EMBO /. 9: 1457-1464.

Wieschaus, E. and W. Gehring. 1976. Clonal analysis of primordial disc cells in the early embryo of Drosophila melanogaster. Dev. Biol. 50: 249-263.

Wieschaus, E. and C. Nüsslein-Volhard. 1986. Looking at embryos. In Drosophila: A practical approach led. D.B. Roberts), pp. 199-226. IRL Press, New York, NY. 


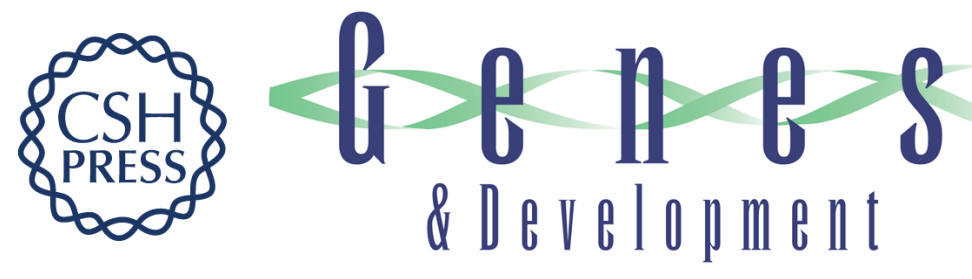

\section{The transcriptional factor CF2 is a mediator of EGF-R-activated dorsoventral patterning in Drosophila oogenesis.}

T Hsu, C Bagni, J D Sutherland, et al.

Genes Dev. 1996, 10:

Access the most recent version at doi:10.1101/gad.10.11.1411

References This article cites 41 articles, 21 of which can be accessed free at:

http://genesdev.cshlp.org/content/10/11/1411.full.html\#ref-list-1

License

Email Alerting

Service

Receive free email alerts when new articles cite this article - sign up in the box at the top right corner of the article or click here.

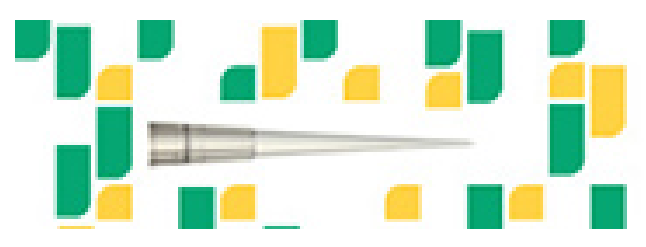

Focused on your science. 